\title{
The reference range of serum magnesium substance concentration among healthy young adults at Makerere University College of Health Sciences 2012
}

\author{
GABRIEL S. BIMENYA 1 , JULIUS OKOT ${ }^{3}$, EMMANUEL OTHIENO², LYNNETTE T. KYOKUNDA ${ }^{1}$, CHARLES IBINGIRA ${ }^{4}$ \\ and ANDREW L. OKWI ${ }^{*}$ \\ ${ }^{1}$ Department of Pathology, School of Biomedical Sciences, College of Health Sciences, Makerere University, Kampala, \\ Uganda \\ ${ }^{2}$ Department of Pathology, Ministry of Health, Mulago Hospital, Kampala, Uganda \\ ${ }^{3}$ Department of Clinical Chemistry, Ministry of Health, Mulago Hospital, Kampala, Uganda \\ ${ }^{4}$ Department of Anatomy, School of Biomedical Sciences, College of Health Sciences, Makerere University, Kampala, \\ Uganda
}

\begin{abstract}
Background: Magnesium is the second most abundant intracellular cation, with only a small proportion of the body's content being in the extracellular fluid. It is required for the active transport of other cations such as calcium, sodium and potassium across the membrane by active transport system. It is also needed for many intracellular metabolic pathways. This study was carried to establish the reference intervals for serum magnesium substance concentration among healthy medical students in Uganda.

Methods: This was purposive study in which ante-cubital venous blood samples were drawn without stasis from 60 healthy, natively Ugandan pre-clinical medical students and analysed without delay using Cobasintegra 400/700/800 automated analyser which flagged each result using the in-built seemingly temperate reference range of $0.65-1.05 \mathrm{mmol} / \mathrm{L}$.

Results: The distribution of serum magnesium substance concentration was unimodal, leptokurtic, and positively skewed with empirical range of $0.86-1.32 \mathrm{mmol} / \mathrm{L}$. There was no result flagged as low. Twenty-six out of sixty (43.3\%) results were flagged as high values while none approached $2.0 \mathrm{mmol} / \mathrm{L}$, considered the threshold of hypermagnesaemia symptoms. Using the central 95 percentile, the reference range was set as $0.81-1.29 \mathrm{mmol} / \mathrm{L}$ which is higher and slightly broader than the $0.65-1.05 \mathrm{mmol} / \mathrm{L}$ often quoted for populations in temperate regions and in-built in automated analysers exported even to the tropics.

Conclusion: Reference ranges were higher in the studied healthy young adults in Uganda than those in the temperate regions. Effort should therefore be made to enable our laboratories establish their own reference values.
\end{abstract}

Keywords: reference, range, serum, magnesium, medical students, Uganda

\section{Introduction}

Magnesium is the fourth most abundant cation in the body and about $50 \%$ of body magnesium is present in the bones in association with calcium and phosphate. The major fraction of body magnesium is found intracellular where it participates in DNA metabolism and protein synthesis while only a small amount of magnesium is found in the extracellular fluid. Magnesium is an activator in various physiochemical processes namely phosphorylation, neuromuscular conduction and excitability of skeletal and cardiac muscles. Dietary magnesium is absorbed in the small intestine where the amount absorbed is inversely proportional to the total body magnesium (Ebel \& Gunther, 1980). The kidneys control magnesium homeostasis through tubular re-absorption when dietary intake is low and excretes excess when dietary intake is high (Bringhurst et al., 2002).

\footnotetext{
${ }^{*}$ Correspondence: andrewol@chs.mak.ac.ug
} 
Increased plasma magnesium concentrations occur in renal failure, acute diabetic acidosis, dehydration or Addison's disease and may depress the central nervous system, causing general anaesthesia with respiratory failure (Jay, 2010). Hypomagnesaemia alters conduction of the heart leading to cardiac arrest and is often observed in chronic alcoholism, malabsorption, severe diarrhoea, acute pancreatitis and kidney diseases. Hypomagnesemia may result in tetany, convulsions and cardiac arrhythmias (Ryan, 1991). Magnesium is widely distributed in foods such as chlorophyll in green vegetables (Bohn et al; 2004), cereals, nuts and meat (Fellows, 2000), which are the most important sources through which the average human replenishes the body needs. Intake in the West is estimated at 10-15mmol/day (Shils, 1988) against the recommended daily of $12.4-16.4 \mathrm{mmol}$ (300400mg) (Seelig, 1986) although growth, pregnancy, lactation or debilitating illness may exert extra demand (Ryan,1991). Chronic alcohol abuse may contribute to magnesium depletion by reduced intake and lowered absorption, worsened by increased renal loss (Ryan \& Barbour, 1998). While thiamine supplementation is a well-established treatment of alcoholic patients, the undoubted importance of magnesium treatment is generally over- looked (Peake et al., 2008).

Magnesium deficiency is found in around 10\% of hospital patients but may occur in over $50 \%$ of patients in intensive care (Swaminathan, 2003). It is important that hospitalized patients following myocardial infarction or with refractory cardiac dysrhythmias, alcoholism, hypokalaemia, diarrhoea, unexplained hypo-phosphataemia, hypo-natraemia orhypo-calcemia, should have serum magnesium determined at least weekly (Ryan, 1991). In such cases, symptoms are likely to respond to treatment only when magnesium is given ((Bohn et al., 2004). Hypocalcaemia is typical of severe hypomagnesaemia and most persons with hypomagnesaemia related hypocalcaemia have decreased PTH levels (Bringhurst et al., 2003). This endocrine relationship raised the curiosity on magnesium levels among our pre-clinical young medical students in their endocrinologycourse shortly before their junior clerkship. This work sought to study the distribution of serum magnesium concentration among healthy young adult Ugandans and to test the transferability of the reference intervals importedly programmed in the automated Cobas Integra 400/700/800 analytical system (Mg 2003-09, V2 En).

\section{Material and Methods}

\section{Sampling Procedure}

Blood samples were taken from 39 males and 21 females natively Ugandan students of the pre-clinical MBChB Endocrine Disorder class in the School of Biomedical Sciences, College of Health Sciences, Makerere University in Uganda. General metabolic diseases had been ruled out from the students through the examination of blood pressure, body mass index (BMI) including carrying out urinalysis using 10-parameter uristix. No signs of kidney disease nor use of anti-acid medication were recorded among the subjects, and there was no haemolysis visibly detected in the serum samples. This study was part of pre-clinical practical sessions in the course of Endocrine Disorders in which the students participated in history taking, providing samples and taking the samples, all done under supervision by the investigators. While the students participated in urinalysis and BMI studies, the investigators only did the serum analysis and the results were anonymously discussed in class.

\section{Laboratory analysis and interpretation of results}

Sixty blood samples, free of haemolysis, taken from students, were analysed for serum magnesium substance concentration using automated Cobas Integra 44/700/800. Serum magnesium substance concentration was calculated and presented as mean concentration in $\mathrm{mmol} / \mathrm{L}$. The programmed range of 0.65-1.05 mmol/L was used to flag off each sample result as normal, low or high which was expected (serum/plasma) values for children and adults (Ryan \& Barbour 1998). 


\section{Data analysis}

The data was analysed using statistical software package STATA 11.0 and summarized using tables and graphs (Altman, 1991).

\section{Ethical considerations}

Permission to carry out the study and publish the findings of this work was sought and granted from the School of Biomedical Sciences Research and Ethics Committee at Makerere University. Study subjects were enrolled after having given in their informed consent to participate in this study.

\section{Results}

Serum magnesium substance concentration in the 60 healthy young adult students ranged from 0.86 to $1.32 \mathrm{mmol} / \mathrm{L}$. The distribution appeared unimodal, mesokurtic and approximately bell shaped with a peak between 0.90 and $1.10 \mathrm{mmol} / \mathrm{L}$ and a slightly positive skew (Figure 1)

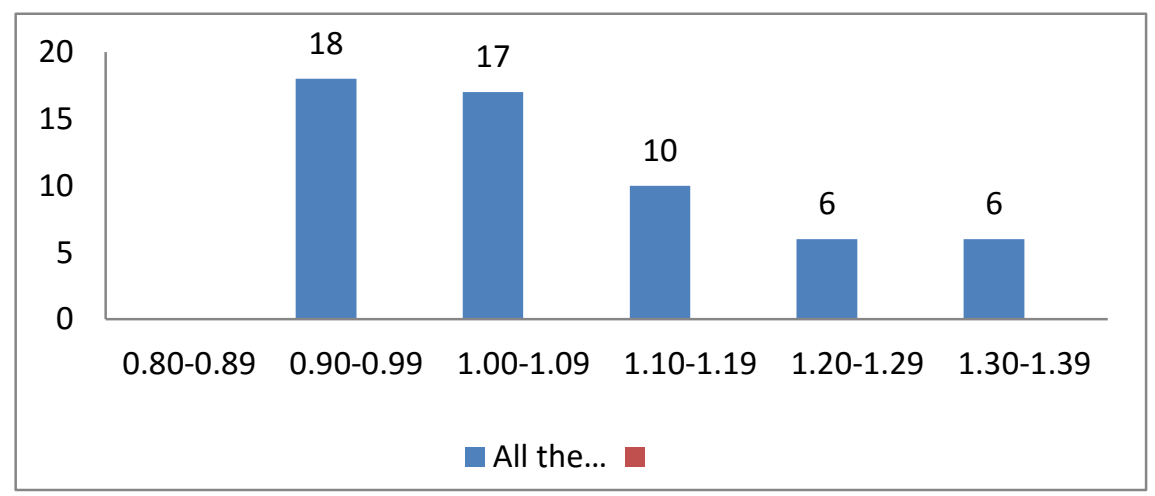

Figure 1: The distribution of serum magnesium among the sixty students

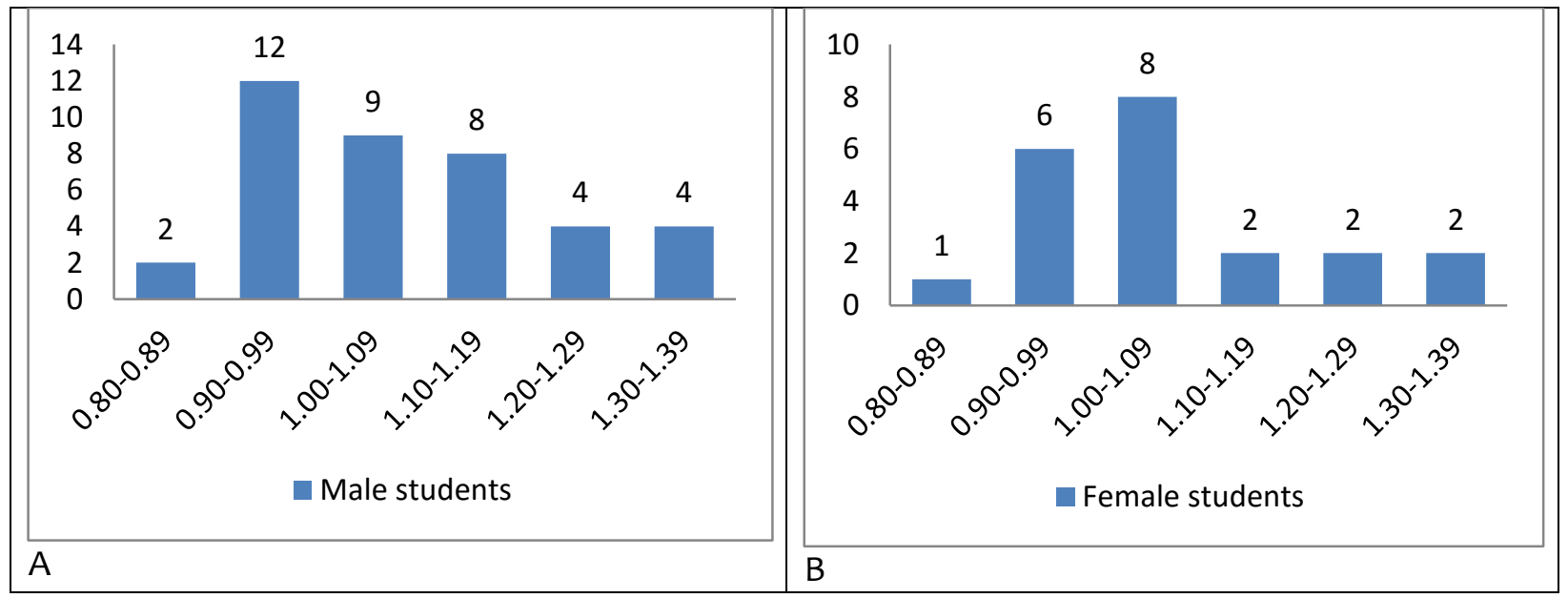

Figure 2: Distribution of serum magnesium among the male (A) and female students (B)

The distribution of serum magnesium among the 39 male students tended to be mesokurtic and peaked between 0.90 and $1.15 \mathrm{mmol} / \mathrm{L}$ (Figure $2 \mathrm{~A}$ ) On the other hand, the distribution of serum 
magnesium among women was unimodal, peaking between 1.00 and $1.10 \mathrm{mmol} / \mathrm{L}$ and was approximately Gaussian normal (Figure 2 B).

\section{Discussion}

The General Medical Council proclaimed in 2003 that medical graduates must have a knowledge and understanding of clinical and basic science. They must be able to follow, safely and effectively the interpretation of the results of commonly used tests in the investigations, and "make clinical decisions based on the evidence they have gathered (General Medical Council, 2003). Beside the edict by the General Medical Council, this work was vindicated by the fact that in their junior clerkship, medical students are responsible for requesting the majority of pathology tests on acutely ill hospital patients (Khromatova\& Gray, 2008). Moreover, prior to this work, magnesium assays were not readily done in Ugandan hospital laboratories as the assay is not included in the essential clinical chemical and haematological tests for intermediate hospital laboratories. The assay was only recently introduced by Heart Institute at Mulago Hospital Complex. So, when this work was proposed as an exercise in Endocrinopathy course, the pre-clinical students, shortly before their junior clerkship, enthusiastically participated, and the results were truly rewarding by helping to discuss the a priori approach of establishing reference values, testing the transferability of reference values, and, most importantly, the distinction between "reference" and "desirable" values (Freedman, 2008).

The use of 60 samples to check reference values of serum magnesium established elsewhere by the same method, and using the similar samples (males=39; females=21) specimens to check the transferability of the inter-sex reference values using the same analytical method had been successfully justified elsewhere (Westergard \& Barry, 1981; Bimenya et al., 2013). What remained was to use the same principles for serum magnesium on healthy Ugandans. There seemed to be no significant difference in the distribution of serum magnesium between males and females. The overall mean was 1.05 and the standard deviation of 0.1202 was much less than 0.5 mean value at $0.50 \mathrm{mmol} / \mathrm{L}$, making it acceptable to determine the reference interval from mean \pm 2 SD (General Medical Council, 2003) as 0.81-1.29 mmol/L.

To the best of our knowledge, this is the first time a serum magnesium reference interval has been reported among healthy Ugandans. It seems different from the $0.70-1.05 \mathrm{mmol} / \mathrm{L}$ imported with the instrument, albeit, with a plea that each laboratory using the Cobasintegra analytical system should establish its local reference values (Mg 2003-09, V2 En).

Magnesium, the second most abundant intracellular cation, acts as a cofactor in many enzymatic reactions and affects neuromuscular function parallel to calcium ion. Magnesium deficiency can result from poor intake, excessive losses or movement from the extracellular fluid to intracellular fluid compartment all resulting in neuromuscular excitability, tachycardia, hypertension or ventricular arrhythmias (Carol, 2006). Excess magnesium is due to renal insufficiency and injudicious use of magnesium medication such as antacids, mineral supplements or laxatives and generally diminishes neuromuscular transmission leading to hyperreflexia, muscle weakness and confusion (Ryan, 1991; Seelig, 1986; Ryan\& Barbour, 1998). No participating student had such signs and symptoms.

Magnesium in serum is measured by a variety of methods. The reference method is atomic absorption spectrophometry which is limited to reference laboratories. The commonly used methods involve complexing magnesium with binders which form compounds of measurable colour changes (Ryan\& Barbour, 1998). The methods used in this study involve binding serum magnesium with cholophosphonazol, causing a measurable increase in absorbance at $659 \mathrm{~nm}$ with EGTA and EDTA added to correct for the non-bound magnesium and the would-be interfering calcium. For traceability, 
the method was reportedly standardized by manufacturers against the reference atomic absorption spectrophotometry while for quality assurance, Precinorm $U$ and Precipath $U$ solutions were used for each batch ( $M g$ 2003-09, V2 En). Nonetheless, though expected results are provided with the equipment system used, each laboratory is encouraged to investigate the transferability of these expected values to its own population and, if possible, to determine its own reference ranges. This was a cardinal goal inthis work on young adult healthy students in their medical training, shortly before clinical clerkship, if for no other reason for their enthusiasm in participating, to make an ounce of practice seemingly greater than a pound of theory (Khromatova \& Gray, 2008).

The generally accepted references range for serum magnesium in the West is $0.65-1.05 \mathrm{mmol} / \mathrm{L}$ (Ebel \& Gunther, 1980) and it was the working reference range given with the automated analytical system used in this work ( $M g$ 2003-09, V2 En). However, it is strongly advised to check its transferability to the population served which, in this case, was the Ugandan population at Mulago Hospital.

The distribution of serum magnesium obtained was unimodal mesokurtic and Gaussian normal so the reference range calculated from mean $\pm 2 S D$ is $1.053 \pm(2 \times 0.1202) \mathrm{mmol} / \mathrm{L}$. Therefore, the reference range of magnesium substance concentration among these subjects is $0.811-1.293 \mathrm{mmol} / \mathrm{L}$, which is very close to but wider than, the working reference range internationally given as 0.65-1.05 $\mathrm{mmol} / \mathrm{L}$ (Mg 2003-09, V2 En). The reference range obtained in this work is consonant with the tropical house-hold magnesium-rich diet of nuts, cereals, greens and leafy vegetables (Fellows 2000) . Magnesium deficiency is common in non-tropical societies (Seelig, 1986; Chipperfield el al., 1976; Karppanen, 1981) where the average western diet may not provide the recommended daily intake (Seelig, 1986) and this gives rise to the high prevalence of cardiovascular disease (Paker et al., 1987; (Altura et al., 1982; Rayssiguier, 1984), myocardial infarction (Liao et al., 1998), coronary vasospasm (Seelig et al., 2004) and premature atherosclerosis (Porth, 2007). All these have been linked to chronic magnesium depletion (Seelig et al., 2004) correctable at variable success rate with magnesium supplementation (Witbay et al., 1988). It would seem (Seelig, 1986; Altura et al., 1982) the staple diet in Uganda is magnesium-rich and is, therefore, highly protective against heart diseases. However, the analytical system used in this work adopted a reference range of serum magnesium of 0.70 $1.05 \mathrm{mmol} / \mathrm{L}$ obviously based on western values such as $0.70-1.00 \mathrm{mmol} / \mathrm{L}$ in USA or $0.70-1.00 \mathrm{mmol} / \mathrm{L}$ in UK (Crook, 2006) or even 0.07-1.15 mmol/L in Dundee (Jahnem-Dechent\& Markus, 2013).

This range was used to flag off values outside the set range and consequently, 27/60 results were flagged off as hypermagnesaemia, ordinarily calling for further scrutiny as the critical difference for magnesium at this level is only $0.4 \mathrm{mmol} / \mathrm{L}$. Due to geographical, racial and other biological sources of variation between individuals as well as differences in analytical methods used, each laboratory should define and publish its own set of reference values (Crook, 2006). This was a cardinal aim in this work, fully supported by the analytical manual of the system used which has been fully justified by the results obtained. As it is very well known that calcium, magnesium and phosphorus metabolism are very closely related and that calcium is very much controlled by vitamin D (Witbay et al., 1988), this study now calls for search for population-based reference intervals of clinical analytes in the tropics where physiological vitamin $\mathrm{D}$ is at the highest level on the globe and the population depends largely on unprocessed fresh foods.

In 2004, the National Institute of Health found that many tropical diets have 10 times as much vitamin $A$ and $D$ as northern diets and that many tropical people are healthier and do not suffer from the "northern" diseases, including certain cancers (Laura, 2004). Since then, Health Institutions in the northern hemisphere have taken seriously winter clinical pathology protocols for investigating magnesium homeostasis such as Magnesium Retention Test, Renal Tubular Re-absorption of 
Magnesium (Rude, 1993) and appropriate Magnesium Supplementation Protocols (Rodríguez-Morán \& Guerrero-Romero (2003).

The reference range of serum magnesium in the healthy students studied was generally higher than the western values by six fold the critical difference, and this implied, among other things, that tropical diet is generally cardio-protective and should be supported. The capacity to measure serum magnesium concentration rapidly, regularly and reliably should be part of the repertoire of all clinical chemistry laboratories involved in the care of critically ill patients (Ryan \& Barbour, 1998). As clinical signs and symptoms of hypo-and hyper-magnesaemia overlap often and are rather nonspecific, physicians are-advised not to wait for clinical signs to occur before checking serum magnesium levels. This means that magnesium should be a core request on every critically ill patient, but populationbased reference values are essential for proper interpretation of the results. Reference ranges were higher in the studied healthy young adults in the tropics as compared to those in the temperate regions. Reference intervals used in our clinical laboratories should be population-based and every effort should be made to enable the laboratories achieve the reference interval establishment.

\section{Acknowledgements}

We wish to acknowledge with thanks the participation of the concerned pre-clinical medical students, the staff of Clinical Chemistry Unit of Mulago Hospital Complex and members of Pathology Department, Makerere University.

\section{References}

Altman, D.G. (1991) Practical Statistics for Medical Research. Chapman and Hall, London

Altura, B.M., Altura, B.T., Carella, A., \&Turlapaty, P.D. (1982) Ca2+ coupling in vascular smooth muscle: $\mathrm{Mg} 2+$ and buffer effects on contractility and membrane Ca2+ movements. Canadian Journal of Physiology and Pharmacology 60, 459-482.

Westergard, J.O., \& Barry, P.L. (1981) Reference Interval Transference. http//www.westergard.com/lesson 30.htm. Accessed on 18/5 2014

Bimenya, G.S., Ibingira, C., Kasolo, J.N., Okot, J.P., Okwi, A.L., Tumwine, L.K., \& Ochieng, J. (2013) Serum aspartate aminotransferase activity concentration among pre-clinical medical students at College of Health Sciences Makerere University. Asian Journal of Health and Medical Sciences 1, 1-10.

Bohn, T., Walczyk, S., Leisibach, S., Hurrell R.F (2004). Chlorophyll-bound magnesium in commonly consumed vegetables and fruits: relevance to magnesium nutrition. Journal of Food Science 69, S347-S350.

Bringhurst, F.R., Demay, M.B., \& Kronenberg H.M. (2002). Hormones and disorders of mineral metabolism. Pp. 1303-1371 in Williams Textbook of Endocrinology, $10^{\text {th }}$ Ed., P.R. Larsen, H.M. Kronenberg, S. Melmed, and K.S. Polonsky, eds. Philadelphia, PA: Saunders.Carol, M.P. (2006) Essentials of Pathophysiology: Concept of Altered States. $4^{\text {th }}$ Ed. Lippincott Williams and Wilkins.

Chipperfield, B. Chipperfield, J.R. Behr, G. Burton, P. (1976) Magnesium and potassium content of normal heart muscle in areas of hard and soft water. Lancet 1(7951), 121-122.

Crook, A.M. (2006) Clinical Chemistry and Metabolic Medicine. $7^{\text {th }}$ Edition. Chapter 6, p114.

Ebel \& Gunther (1980) Magnesium metabolism: a review. Journal of Clinical Chemistry and Clinical Biochemistry 18, 257-270. 
Fellows, P.J. (2000) Food Processing Technology: Principles and Practice, $2^{\text {nd }}$ Edition, Parts 1-4 Publishers: Amazon.comFreedman, D.B. (2008) Is the medical undergraduate curriculum 'fit for purpose'?. Annals of Clinical Biochemistry 45, 1-2.

General Medical Council (2003) Tomorrow`s doctors London: General Medical Council, 2003. http:ww.gmc-uk.org/education/undergraduate/tomorrow.pdf. Accessed on 5/6/2014

Jahnem-Dechent, W., \& Ketteler, M. (2013) Magnesium basics. Clinical Kidney Journal 5 (Suppl), i3 - i14. Jay, W.L. (2010) Fluid and Electrolyte Disturbances in Critically III Patients.Electrolyte Blood Press 8, 7281.

Karppanen, H. (1981) Epidemiological studies on the relationship between magnesium intake and cardiovascular disease. Artery 9, 190-199.

Khromatova, V., \& Gray T.A. (2008) Learning needs in clinical biochemistry for doctors in foundation years. Annals of Clinical Biochemistry 45, 33-38.

Laura, P. (2004) Vitamin D-The Winter Deficiency. www.laurapower.com/page24.html. Accessed on $18^{\text {th }}$ June 2015.

Liao, F., Falson, A.T. \& Brancari, F.L. (1998) Is low magnesium concentration a risk factor for coronary heart disease? The atherosclerosis risk in communities (ARIC) study. American Heart Journal $136,480-490$.

Mg 2003-09, V2 En: Magnesium assay method in English for determination of magnesium in serum/ plasma on COBAS Integra 400/700/800 automated analyzer of Roche Diagnostics GmbH D68298 Manheim.

Paker, M., Gottlieb, S.S., \& Blum, M.A. (1987) Immediate and long term Pathophysiologic mechanisms underlying the genesis of sudden cardiac death in patient with congestive heart failure. American Journal of Medicine 7, 82 (Suppl 3A), 4-10.

Peake, R.W.A., Godber, I.M. \& Maguire, D. (2008) The effect of magnesium supplementation in the treatment of chronic alcoholic patients in the acute setting. Annals of Clinical Biochemistry 45 (Suppl 1), 36T24.

Porth, C.M. (2007) Essentials of Pathophysiology Concepts of Altered Health States $2^{\text {nd }}$ Edition. Lippincott Williams of Wilkins.

Rayssiguier, Y. (1984) Role of magnesium and potassium in the pathogenesis of arteriosclerosis. Magnesium 3, 226-238.

Rodríguez-Morán, M. \& Guerrero-Romero, F. (2003) Oral magnesium supplementation improves insulin sensitivity and metabolic control in type 2 diabetic subjects. A randomized double-blind controlled trial. Diabetes Care 26, 1147-1152.

Rude, R.K. (1993) Magnesium metabolism and deficiency. Endocrinology and Metabolism Clinics of North America22, 377-395.

Ryan, M.F., \& Barbour, H. (1998) Magnesium measurement in routine Clinical practice: Annals of Clinical Biochemistry 35, 449-459.

Ryan, M.F. (1991). The role of magnesium in clinical biochemistry: an overview Annals of Clinical Biochemistry 28, 19-26.

Seelig, M.S. (1986) Nutritional status and requirements of magnesium; with consideration of individual differences and prevention of cardiovascular disease. Magnesium Bulletin 8, 170-85.

Seelig, M.S., Altura, B.H. \& Altura, B.T. (2004) Benefits and risks of sex hormone replacement in menopausal women. Journal of American College of Nutrition 482, S482S-496.

Shils, M.E. (1988) Magnesium in health and disease. Annual Review of Nutrition 8, 429-480.

Swaminathan, R. (2003) Magnesium metabolism and its disorder. Clinical Biochemist Review 24, 47-66

Witbay, L.G., Smith, A.F. \& Beckett, G.J. (1988) Lecture Notes on Clinical Chemistry. $4^{\text {th }}$ Ed. Blackwell Scientific Publications, London, 38-178. 